\title{
Continuous Casting of Steel Billet with High Frequency Electromagnetic Field
}

\author{
Joonpyo PARK, Hoyoung KIM, Heetae JEONG, Goohwa KIM, Myung Jong CHO, Jea-Sook CHUNG, \\ Minsu YOON, Kyung Ryul KIM"1) and Joo $\mathrm{CHOl}^{2)}$
}

Research Institute of Industrial Science and Technology, P.O.Box 135 Pohang, 790-600 Korea.

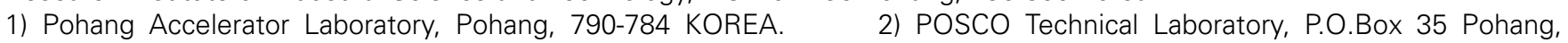
790-360 Korea.

(Received on November 27, 2002; accepted in final form on January 28, 2003)

\begin{abstract}
The electromagnetic continuous casting technology has been investigated in commercial scale casting experiments at a billet caster of POSCO works. A set of facility composed of coil \& mold with a specially devised molten metal level meter, and software for casting monitoring were well suited to No. 2 billet caster of POSCO. The devised EMC facility and software proved well working and good enough for commercial production in the viewpoint of cooling capability of the mold, control of molten steel level. The major observations with the electromagnetic continuous casting operations include that the oscillation mark was improved a lot to its nominal depth of less than $0.1[\mathrm{~mm}]$, and that the solidified shell thickness at the mold bottom was increased $10 \%$. It was also seen that the mold powder consumption increased up to $30 \%$, and that a continuous casting without mold oscillation was possible with excellent surface quality of the billet. The billet surfaces to the various amounts of mold flux consumption suggested that the choice of the mold flux be one of the important elements to enjoy the electromagnetic effects. Finally, it is worthwhile to emphasize that the electromagnetic continuous casting can help to prevent breakouts and to relieve the mold oscillation, besides the well-known effects of surface improvement.
\end{abstract}

KEY WORDS: electromagnetic casting; oscillation mark; continuous casting; solidified shell; surface roughness; Joule heat.

\section{Introduction}

Electromagnetic field has capabilities of applying physical force (Lorentz force) and energy (Joule heat) to electrically conducting materials without any contact. ${ }^{1)}$ The energy transfer function has been utilized in metal processing for induction heating and melting over the years. Since the 1970 's, the Lorentz force has been utilized as an electromagnetic stirrer (EMS) and a mold-less casting of aluminum, named electromagnetic continuous casting (EMC) technology, in the continuous casting process.

EMC had an attraction in enhancing the surface quality of the casting strands of aluminum to be fed to the rolling process without surface treatment. It was easily achieved owing to high electric conductivity and low specific weight of aluminum. ${ }^{2,3)}$ After that, the aluminum EMC has been developed in the way not only to provide excellent surface quality, but also to enhance the inner quality of the strands. $^{4-6)}$ Several million tons of aluminum slabs have been produced globally with this EMC technology.

In steel casting process, the EMC technology has been anticipated as a key process for a continuous in-line manufacturing process from casting to rolling. The strands without any surface defects will open the possibility of the direct rolling operation with hot strand. Owing to the material property, for example a relatively high specific weight and low electric conductivity and a faster casting speed compared to aluminum, mold-less casting proved nearly impossible for steel. As a break-through, the method of employing mold, so-called soft contact type, has been devised. Since the 1980's extensive research has been undertaken in Japanese universities and industry research centers. ${ }^{7-9)}$ The two methods has been considered: the one uses the mold of cold crucible type with high frequency electric power, ${ }^{9,10}$ and the other uses conventional mold with relatively low frequency electric power of several hundred $\mathrm{Hz} .{ }^{11)}$ It has been widely understood that the high frequency EMC may have obstacles in devising mold and power supply and the low frequency EMC in getting stable molten metal level at casting operation. In both cases, main process parameters for good strand surface include the relative position between the coil and the molten metal level, the mold flux as well as the intensity of electromagnetic field. ${ }^{12-14)}$

As a part of the research of the high frequency EMC technology, ${ }^{15,16)}$ the present study reports the results of the commercial scale casting experiments at a billet caster of POSCO.

\section{Physical Concept of Electromagnetic Casting}

The working principle of the high frequency EMC, shown schematically in Fig. 1, is briefly explained. The left 


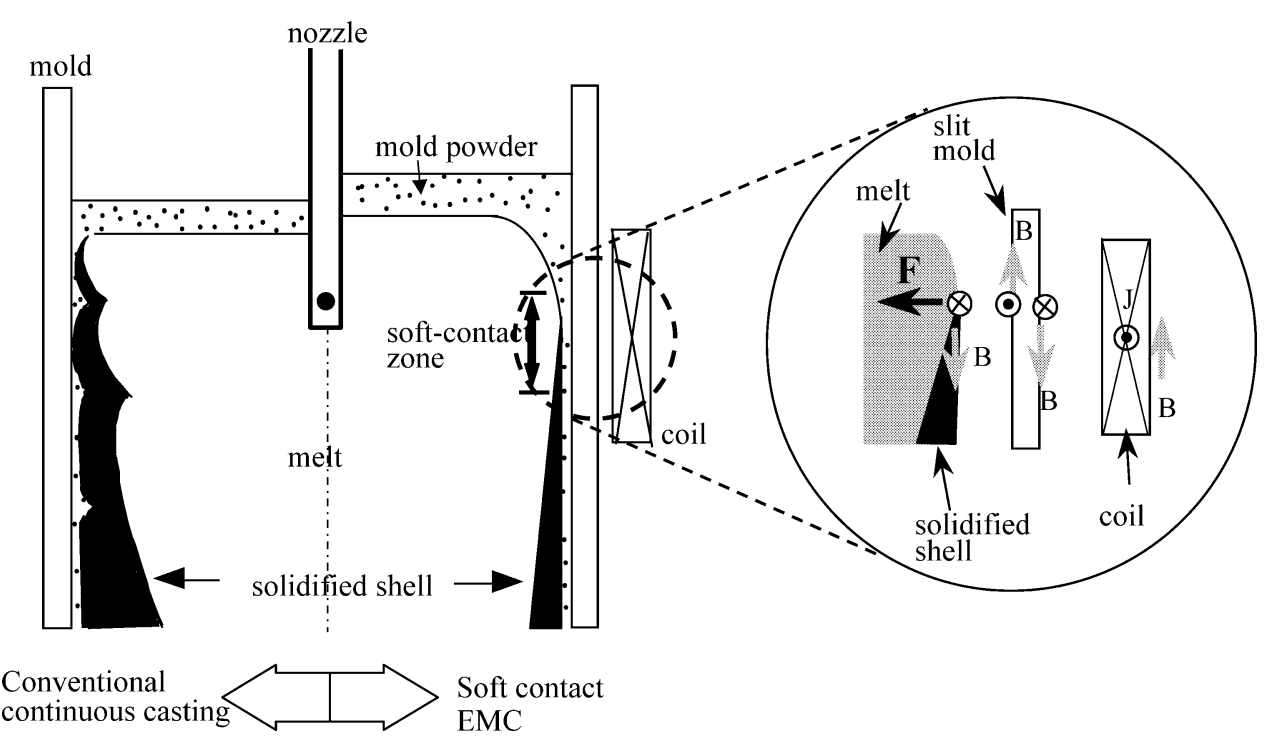

Fig. 1. Schematic figure in the mold of conventional and electromagnetic continuous casting of steel.

side represents the conventional casting and the right side represents the EMC. The EMC needs special devices to apply the magnetic field to the melt; a coil is provided additionally and the mold needs to be sectioned like the cold crucible particularly for the high frequency EMC. Meanwhile, the mold for the low frequency EMC is identical to the conventional mold. The magnetic field generated from the coil induces electric current in the melt. Then, this current heats up the melt in terms of Joule heat and further generates body force, so-called Lorentz force, together with the external magnetic field in the melt, where the force always directs inward. The EMC utilizes such energy and force all together to attain defect-free surface and subsurface of the strands.

In the conventional casting, the meniscus is in touch with the mold wall almost at a right angle. Its solidification initiates with a hook, known as an origin of oscillation mark (OSM)s, and consequently OSMs develop on the surface of casting strands. In the EMC, the inward Lorentz force deforms the meniscus so much as to be curved near the mold wall. This will help the flux infiltrate well into the gap between the strand and the mold wall. The Joule heat generated in the melt near the mold wall affects the solidification to take place below the meniscus without any form of the hook. The Joule heat generated in the melt near free surface supplies extra energy to the mold powder, and helps its melting without excessive heat loss of the molten metal. Thus, the EMC process is expected to yield cast products with neither OSMs nor related surface defects, and to increase the amount of mold powder consumption.

\section{Apparatus for Electromagnetic Casting and Casting Conditions}

The mold plate was the copper alloy identical to the material used in POSCO's billet casting operation. Its length was $800 \mathrm{~mm}$, the size of casting section was $163 \times 163 \mathrm{~mm}$ and an inside corner radius of $8 \mathrm{~mm}$. The mold adapted to the cold crucible concept was designed for incoming cooling water from the mold bottom and outgoing to the top of the mold by means of 6 holes of $10 \mathrm{~mm}$ in diameter at each face and one hole at each corner, respectively so that cooling water can flow inside the wall plate. In some sections between the cooling water pass, machining was made for the longitudinal gap of $0.3 \mathrm{~mm}$ thick, where feldspar plates were inserted for electrical insulation. In Fig. 2, a mold photo and mold sections divided are illustrated. The inductor coil to provide magnetic field was 6 turns and fixed around the outside of the mold.

At the top of the mold, magnetic induction type level sensor ${ }^{17)}$ was fabricated. Molten metal level was remotely measured by $0.05 \mathrm{~s}$, and the measured data were input to the Mold Level Automatic Controller (MLAC) with the precision of $0.3 \mathrm{~mm}$.

In order to monitor the temperature of the mold plate in real time, $26 \mathrm{~K}$-type non-ground thermocouples were inserted at $10 \mathrm{~mm}$ intervals in the casting direction from $50 \mathrm{~mm}$ away from the top of the mold to a distance of $6 \mathrm{~mm}$ from the inside face of the mold. A measurement device was built using a DAQ Card AI-16XE-50 and AMUX-64T from the National Instruments Company in the USA. Measurements were made remotely each second using the LabVIEW program.

To measure the temperature variations of the cooling water of the mold in real time, 29 RTD thermocouples were installed in the cooling water inlet and outlet side of the mold. A signal processing device was built for remote measurement using SCXI-1200, SCXI-1122, SCXI-2400 and RS-485 interface board from the National Instruments Company in the USA. Its measurement result was monitored and stored each second. Cooling water temperature data was fed into the computing software to calculate the solidified shell thickness at the mold bottom in real time during casting.

A conceptual drawing of the EMC device installed in a POSCO's billet casting machine is illustrated in Fig. 3. The molten metal was maintained at the designated level by adjusting the molten steel supply volume with the MLAC. Parts that were different from the existing continuous casting equipment were molten metal sensor, mold and coil, and power source equipment, which is the part enclosed by the dotted line in Fig. 3. An electromagnetic stirrer, operat- 


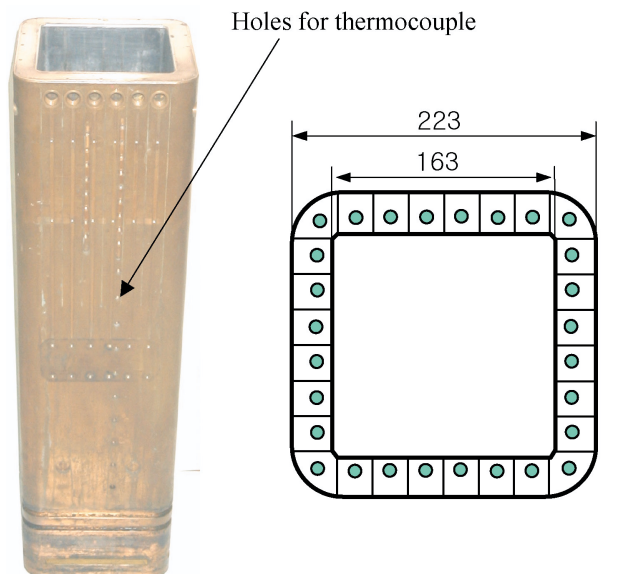

Fig. 2. EMC mold and its cross-sectional shape near the meniscus.

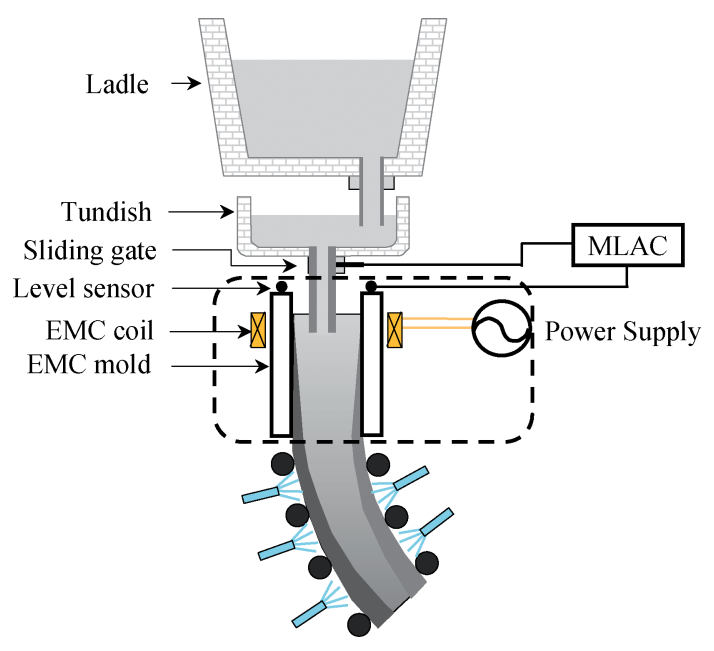

Fig. 3. Schematic figure of the EMC billet caster at POSCO.

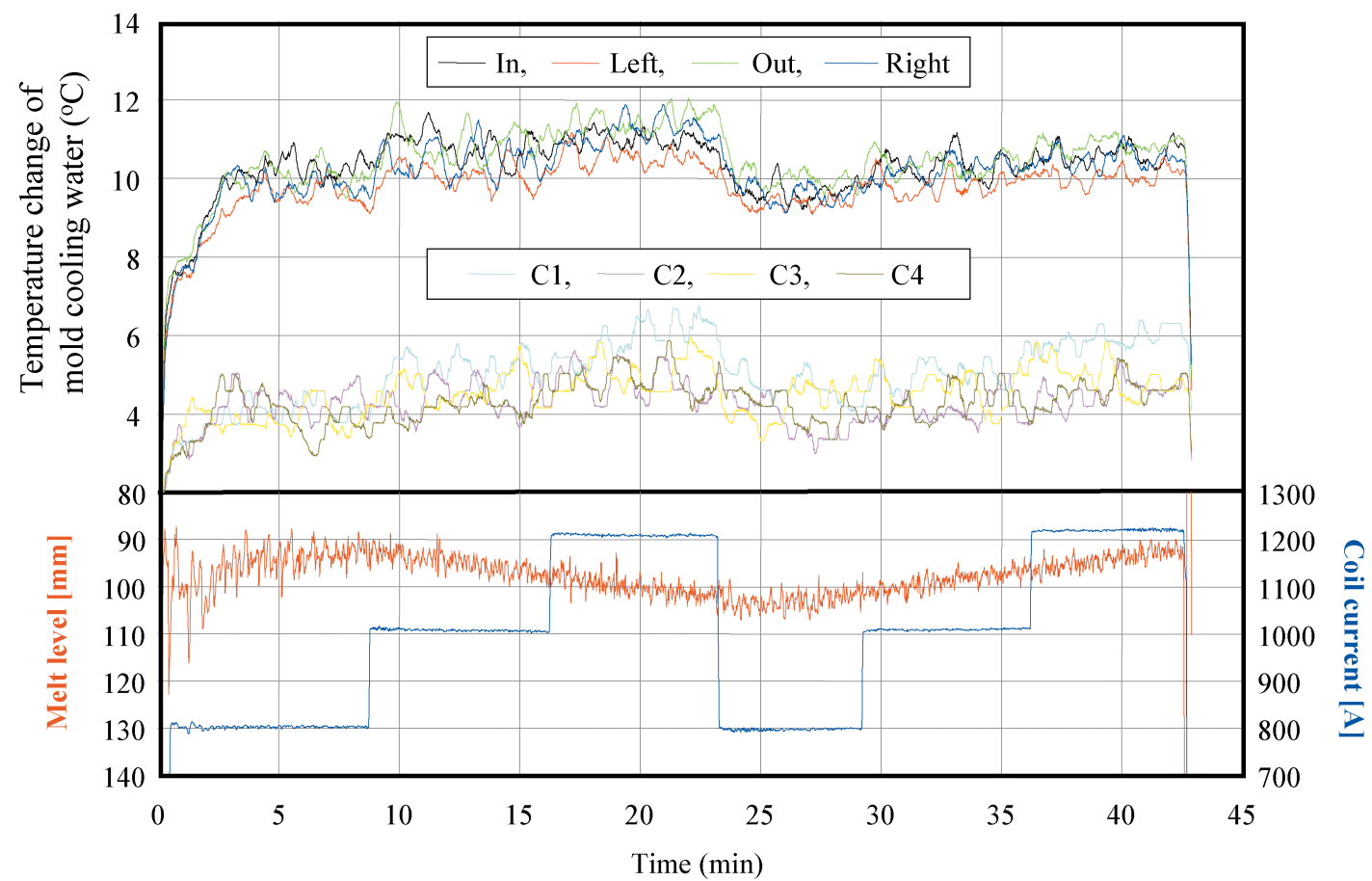

Fig. 4. A typical monitoring results of temperature change of mold coolant, melt level, and coil current.

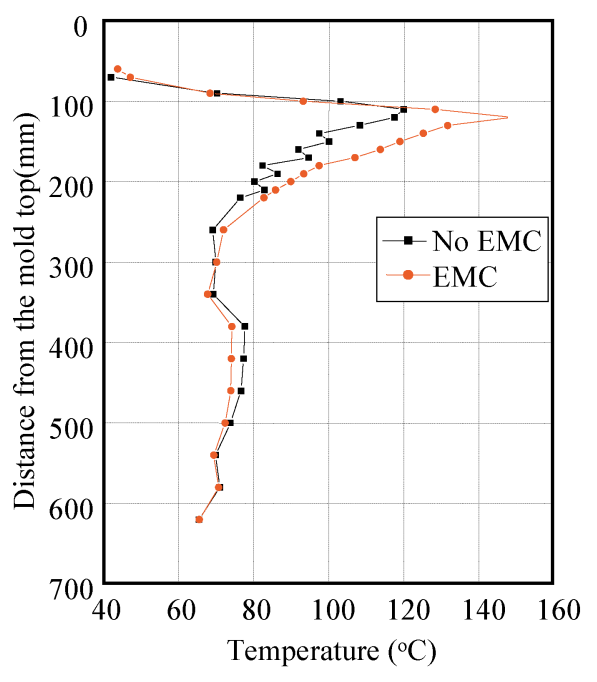

(a)

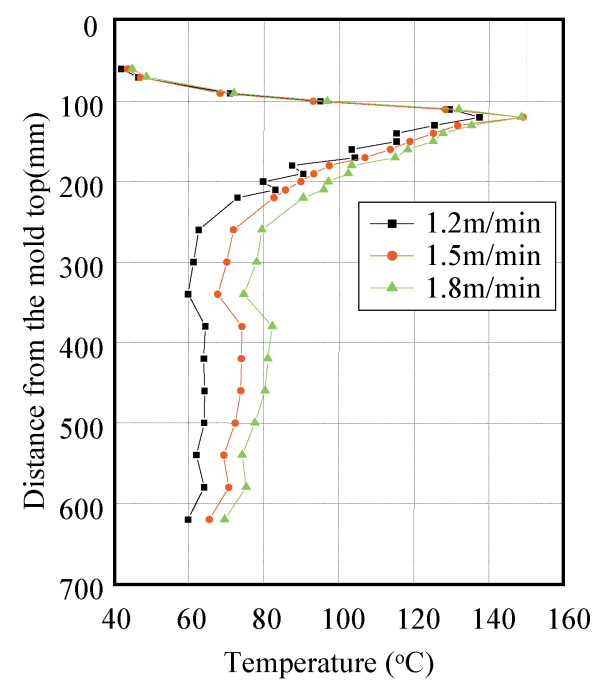

(b)
Fig. 5. Temperature field of the mold plate with the melt level of 100 [mm]. (a) Conventional casting versus EMC with coil current 1000 [A]. (b) Effect of the casting speed at EMC with coil current $1000[\mathrm{~A}]$. 
Table 1. Experimental conditions

\begin{tabular}{|l|l|}
\hline Metal & $0.1 \% \mathrm{C}$ steel \\
Billet size & $163 \mathrm{~mm}$ square \\
Casting speed & $1.2-1.8 \mathrm{~m} / \mathrm{min}$ \\
Mold lubricant & mold flux \\
Electric conditions & \\
Frequency & $20 \mathrm{kHz}$ \\
Coil current & $0-1200 \mathrm{~A}$ \\
\hline
\end{tabular}

ed at $8[\mathrm{~Hz}] / 200[\mathrm{~A}]$, was installed in the mold assembly and its top was located at $100[\mathrm{~mm}]$ below from the bottom of the EMC coil. Capacity of power supply was $200 \mathrm{~kW}$ and the frequency range was $10-30[\mathrm{kHz}]$.

$\mathrm{Fe}-0.1 \mathrm{wt} \% \mathrm{C}$ steel was employed for the casting material and melt temperature at the tundish varied from 1570 $1530\left[{ }^{\circ} \mathrm{C}\right]$. The total amount of cooling water of the mold was $1050[\mathrm{l} / \mathrm{min}]$. Casting conditions were shown in Table 1, where the parameters were EMC coil current, casting speed, mold flux, and mold oscillation.

The degree of surface improvement in billets was evaluated by measuring the surface roughness with a profile shape measurement device. To analyze any metallurgical effect of the electromagnetic field, billets produced by the conventional method and by various electromagnetic conditions were compared. Secondary dendrite arm space (2nd DAS) at the subsurface region was measured for each specimen.

\section{Results and Discussion}

\subsection{EMC Operation}

Figure 4 shows a typical monitoring result of the EMC operation. Thermal history of cooling water in the mold, molten steel level, and coil current were shown in the Figure. In the upper figure, the temperature changes of the mold cooling water at the designated positions were shown, where the temperature changes were evaluated as the water temperature at the exit of the water channel minus the water temperature at the entrance of the water channel of the mold at every segment. 'In', 'Left', 'Out', and 'Right' curves denote mean values at the mold faces, and ' $\mathrm{C} 1$ ', ' $\mathrm{C} 2$ ', ' $\mathrm{C} 3$ ', and ' $\mathrm{C} 4$ ' curves are those at the four corners of the mold, respectively. It is noted that the temperature variations at the mold cooling water reflect the variation of the coil current, since the amount of Joule heat developed in the melt and the mold depends on the coil current. It was also recognized that relatively good control of molten steel level was achieved.

Figure 5(a) shows temperature distributions in the mold plate of the EMC operation at 1000 [A] and the conventional casting. The molten steel level was controlled at $100[\mathrm{~mm}]$ below from the mold top. The two observations were the location of the peak temperature and the higher temperature in the EMC operation. In the conventional casting, the highest temperature position of the mold plate was just below the molten metal level (100-120 mm), while in the EMC the position was $110-130 \mathrm{~mm}$. This could be explained by considering the fact that the contacting position of the melt to the mold wall in EMC would be lower than that in conventional casting owing to the melt curva-

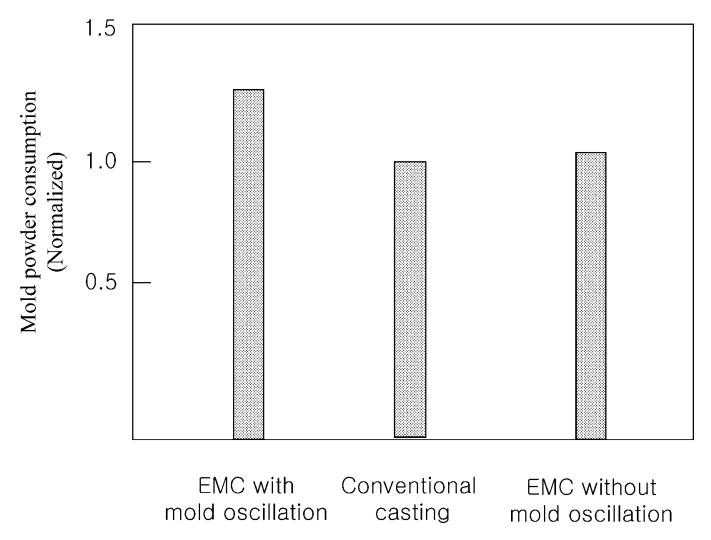

Fig. 6. Mold powder consumption versus casting conditions.

ture formed by magnetic force.

The temperature of the mold plate in the EMC operation was higher than that in the conventional casting to the position of $300 \mathrm{~mm}$ from the molten metal level, elsewhere the temperature was almost same. The high temperature in the EMC could be explained as both the effects of Joule heat by the induced current and the increase of the heat flux transferred from the melt, where the latter will be discussed with solidified shell thickness.

Figure 5(b) shows mold plate temperature versus casting speed. The widely known fact that higher temperature was seen for faster casting speed was also confirmed with the EMC operation.

The amount of the mold powder consumption of the EMC operation is shown in Fig. 6 for various casting conditions compared to the conventional casting operation. In the EMC operation, it was in the range of $110-130 \%$ of the conventional casting. This can be explained as the work of the magnetic force in such a way that the magnetic force made the meniscus into a curved shape, and thus the mold flux would easily flow into the gap between the strand and the mold wall. Joule heat also helped in melting the powder and in keeping the molten flux at relatively high temperature compared to the conventional casting. Particularly, it is noteworthy that the mold powder consumption in case of EMC without mold oscillation was no less than that of the conventional casting.

\subsection{Effect of Coil Current on the Surface Quality}

Figure 7 shows typical billet surfaces for various coil currents with a mold powder of $22[\mathrm{wt} \%]$ carbon and 7 [poise] viscosity, and Fig. 8 shows the surface roughness measured. In case that the coil current was $0[\mathrm{~A}]$, i.e. the conventional casting, billets had the OSMs of its nominal depth in the range of $0.45 \pm 0.15[\mathrm{~mm}]$. When the coil current was 500 [A], the OSM disappeared a lot to its nominal depth in the range of $0.20 \pm 0.05[\mathrm{~mm}]$ except the corner region. When the coil current was 1000 [A], the OSM disappeared everywhere to its nominal depth in the range of $0.10 \pm 0.04[\mathrm{~mm}]$. When the coil current increased to 1200 [A], the OSM appeared again in the form of wave mark $^{15)}$ although its nominal depth was not severe in the range of $0.18 \pm 0.05$ [mm]. Besides, the slit marks was observed. These observations are similar to those of the laboratory casting of $\operatorname{tin}^{15)}$ and steel. ${ }^{16)}$ Thus, the optimum coil current seemed about 1000 [A]. 


\subsection{Mold Flux Consumption and the Surface Quality}

Mold flux may also be an effective in the surface quality.

Figure 9 shows EMC billets of the identical casting speed

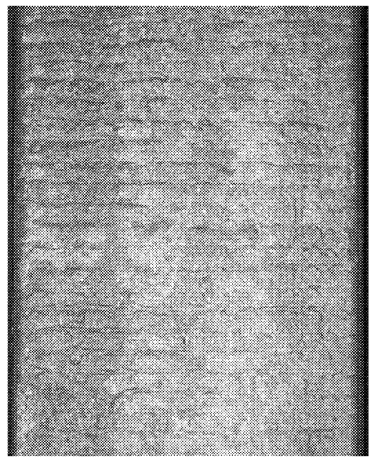

(a) $0 \mathrm{~A}$

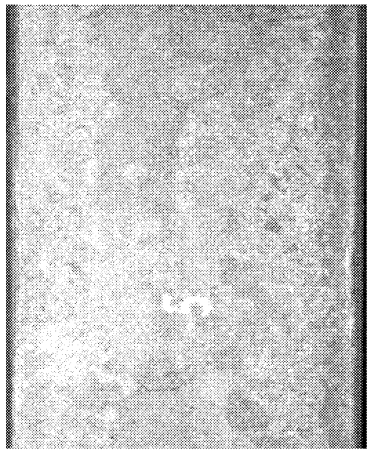

(c) $1000 \mathrm{~A}$

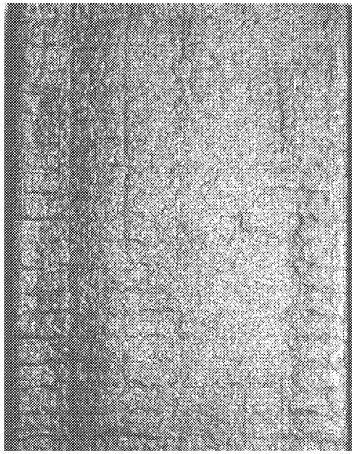

(b) $500 \mathrm{~A}$

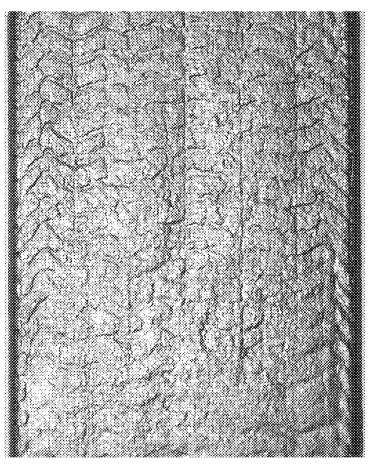

(d) $1200 \mathrm{~A}$
Fig. 7. Typical appearance of billet strands.

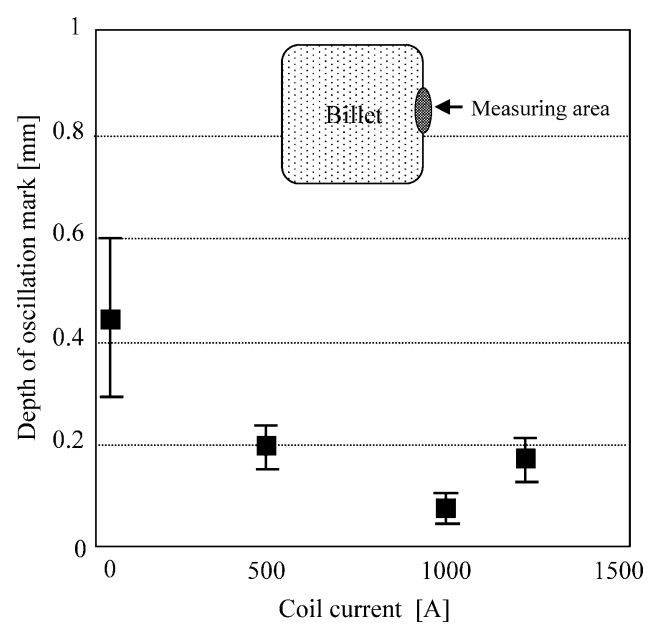

Fig. 8. Depth of oscillation mark of billet strands.
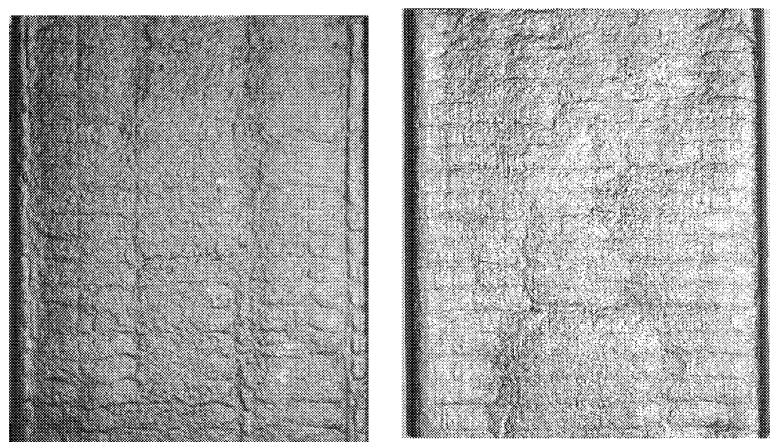

(a) $22 \% \mathrm{C}, 10$ [poise] (b) $22 \%$ C, 7 [poise]

and the coil current with various mold flux. The carbon content for (a) and (b) was $22[\mathrm{wt} \%]$, and for (c) and (d) was $0.5[\mathrm{wt} \%]$. Its viscosity at $1300\left[{ }^{\circ} \mathrm{C}\right]$ was (a) 10 [poise], (b) 7 [poise], (c) 10 [poise], and (d) 15 [poise], respectively. The consumption of mold flux was measured as (a) 0.25 , (b) 0.44 , (c) 0.61 and (c) 0.59 [kg/ton], respectively, which gave the slag film thickness calculated as (a) 28.8, (b) 51.4, (c) 74.1 , and (d) $69.4[\mu \mathrm{m}]$, respectively. Billet (a) showed a nominal OSM of $0.35[\mathrm{~mm}]$ with slit marks at the positions corresponding to the mold slit. Billet (b) had a nominal OSM of $0.20[\mathrm{~mm}]$ with no slit marks. In billets (c) and (d), OSMs were completely disappeared, but longitudinal depressions appeared similar to the case of the excessive amount of mold flux. The billets denote that although the casting conditions except the mold flux were almost identical, the effect of electromagnetic field on the billet surface was drastically different. These observations could be explained with a viewpoint of the cooling capability of the mold near the meniscus region, since the slag film thickness could be a measure to the gap between mold wall and strand. When the gap between mold wall and strand decreased, the cooling capability of the mold increased to relieve the effect of the electromagnetic field. Thus the OSMs developed, although the amount of Joule heat and magnetic force maintained as constant. When the gap increased, it would be vice versa. In billets shown in Fig. 9, the amount of Joule heat seemed adequate, and a small variation of the heat flux of the mold plate seemed to determine the surface quality. In other words, the balance between the heat flux of the mold plate and Joule heat was a crucial element for the OSM formation. This supports the postulate that the OSM formation in high frequency EMC is governed by Joule heat rather than magnetic force. ${ }^{15)}$

\subsection{Effects on 2nd DAS}

Figure 10 shows 2nd DAS of the billets from the surface to $16[\mathrm{~mm}]$ by $4[\mathrm{~mm}]$ for various electromagnetic conditions. It is widely accepted that the 2nd DAS of the strand monotonically increases from the surface to the center due to the decrease of cooling rate. But the EMC billets showed a different pattern; its value at the surface was almost same as that of the subsurface. This supports the fact of slower cooling rate due to Joule heat at the time of the early solidification since the electromagnetic field in EMC worked just at the coil region. In EMS billet, large DAS were found to the depth of 12 [mm] from the surface, because stirring of the melt made slower cooling rate in the whole mold length.

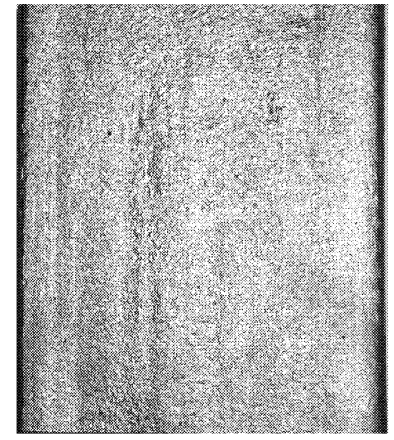

(c) $0.5 \% \mathrm{C}, 10$ [poise]

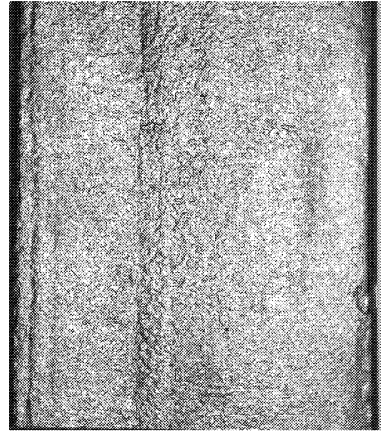

(d) $0.5 \% \mathrm{C}, 15$ [poise]

Fig. 9. Appearance of billets of coil current $1000[\mathrm{~A}]$ and casting speed $1.5[\mathrm{~m} / \mathrm{min}]$ with several kinds of mold powder. 


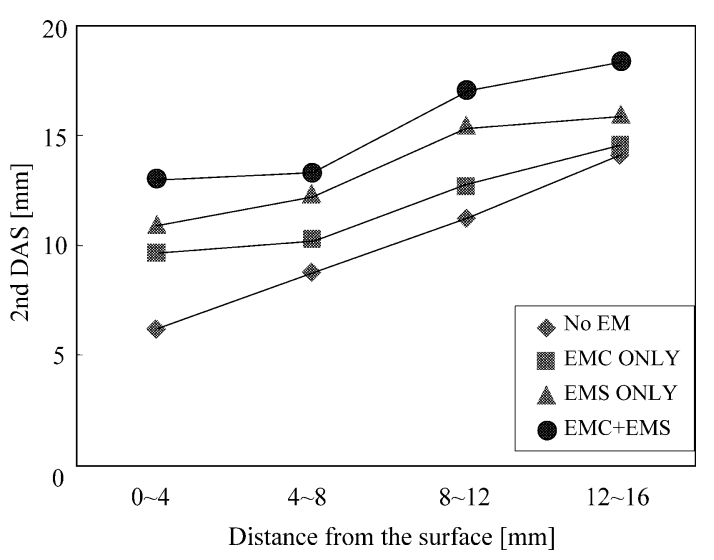

Fig. 10. 2nd dendrite arm spacing (2nd DAS) at subsurface of the billets with casting speed $1.5[\mathrm{~m} / \mathrm{min}]$. (a) Conventional casting, (b) EMC only: EMC of coil current $1000[\mathrm{~A}]$, (c) EMS only: EMS of coil current 225 [A], (d) EMC+EMS: EMC of coil current 1000 [A] and EMS of coil current 225 [A].

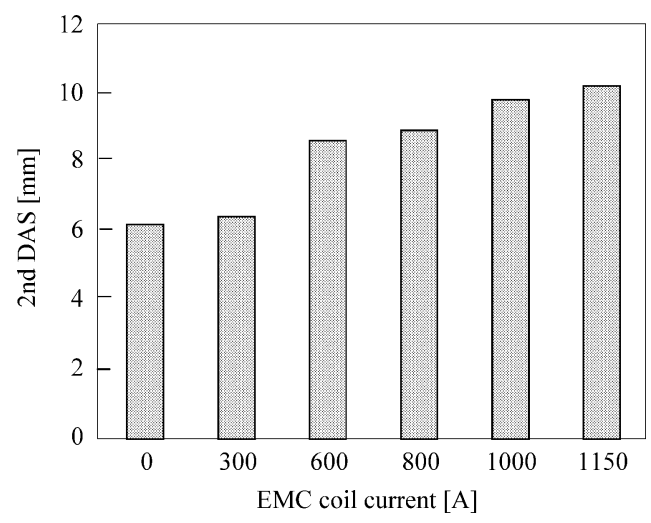

Fig. 11. EMC coil current versus 2 nd dendrite arm spacing (2nd DAS) at subsurface region of the billets with casting speed $1.5[\mathrm{~m} / \mathrm{min}]$.

In case of EMC+EMS, both effects of Joule heat and stirring were observed.

Figure 11 shows effect of applied current on the 2nd DAS. To the $300[\mathrm{~A}]$ of coil current, DAS is same as that of conventional casting, but from 600 [A] DAS increases as current increases. It was considered that with current less than 300 [A], the amount of Joule heat was insufficient to make an effect. This suggests that the coil current starting to affect the DAS would be determined by the balance between the cooling capacity of the mold and the amount of the Joule heat.

\subsection{Effects on Solidified Shell Thickness}

It is possible to calculate the solidified shell thickness at the bottom of the mold using the data of the temperature change of the mold cooling water shown in Fig. 4. From the data of temperature change of the mold cooling water, the total heat was evaluated. When the effect of Joule heat both in the mold and in the billet was subtracted from the total heat, the remainder would be equal to the energy that the melt lost. Then, the mean solidified shell thickness at the mold bottom could be evaluated and was shown in Fig. 12. In the figure, the black circle represents solidified shell thickness of coil current 1000 [A] and the white circle rep-

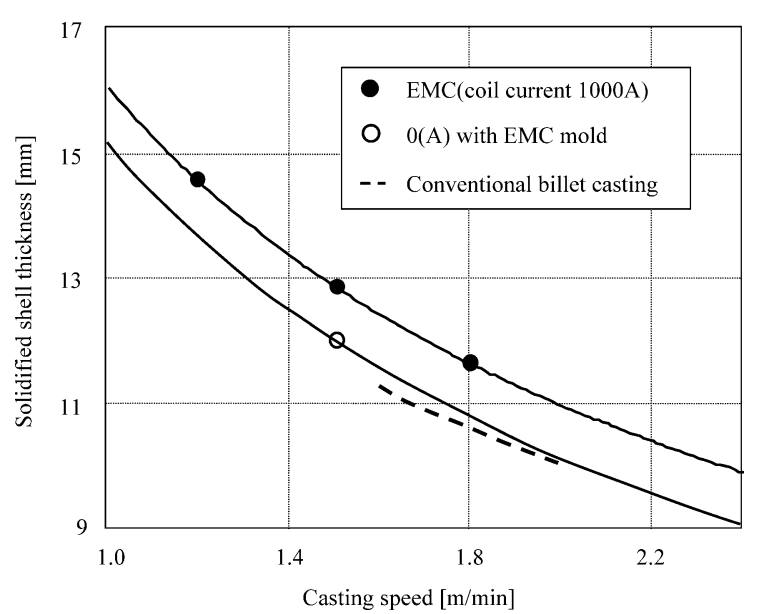

Fig. 12. Solidified shell thickness versus casting speed at the bottom of mold.

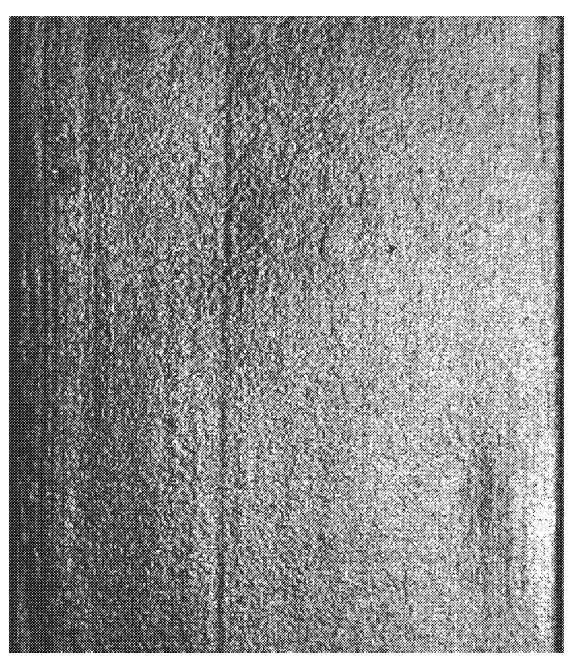

Fig. 13. Appearance of billet strands of coil current $1000[\mathrm{~A}]$, no mold oscillation and the casting speed of $1.5[\mathrm{~m} / \mathrm{min}]$.

resents it of $0[\mathrm{~A}]$, that is conventional casting. The results show that EMC has a solidified shell thickness of about $10 \%$ increase, similar to the result of tin experiment. ${ }^{15)}$ This appears to be caused by the improved surface flatness of the billet, that is reduction of the OSMs. In case of the strand with flat surface, the gap between the mold and the strand is uniform and thus the heat amount transferred from the strand to the mold increases. Therefore the solidified shell thickness in the mold can be thicker in EMC than in conventional casting, although Joule heat is supplied. This result suggests that EMC help to prevent breakouts and make the casting operation more stable.

\subsection{EMC Operation without Mold Oscillation}

In the conventional continuous casting of steel, the mold moves up and down for the purpose of preventing the melt from sticking to the mold and of enhancing the mold flux to infiltrate well to the gap between the mold wall and the strand. In EMC operations, the consumption of the mold flux proved sufficient and it was expected that Joule heat would work to encourage the fluidity of the mold flux. Based on this reason, the casting without mold oscillation was thought to be possible. Figure $\mathbf{1 3}$ is a photograph showing the surface of the billet cast without mold oscilla- 
tion of the coil current 1000 [A]. The surface was greatly improved to the roughness below $0.1[\mathrm{~mm}]$, and better than the billets cast with mold oscillation shown in Fig. 7. This suggests that the continuous casting without mold oscillation will be possible with EMC and that the EMC can contribute to the simplification of the oscillator as well as to the improvement of the surface quality of strands.

\section{Conclusions}

Electromagnetic continuous casting apparatus was suited on a billet caster of POSCO works, and commercial scale casting test was successfully performed. First of all, the devised EMC facility and software proved well working and good enough for commercial production in the viewpoint of cooling capability of the mold, control of molten steel level. The major observations with the EMC operation include that the oscillation mark was improved a lot to its nominal depth of less than $0.1[\mathrm{~mm}]$, and that the solidified shell thickness at the mold bottom was increased $10 \%$. It was seen that the mold powder consumption increased up to $30 \%$, and that a continuous casting without mold oscillation was possible. The billet surfaces to the various amounts of mold flux consumption suggested that the choice of the mold flux be one of the important elements to enjoy EMC effects. Finally, it is worthwhile to emphasize that the EMC can help to prevent breakouts and to relieve the mold oscillation, besides the well-known effects of surface improvement.

\section{REFERENCES}

1) M. Zahn: Electromagnetic Field Theory, Robert E. Krieger Publishing Company, Inc., Malabar, Florida, (1979).

2) Z. N. Getslev: US Patent No 3467166, (1969).

3) J. P. Riquet and J. L. Meyer: Light Metals, (1987), 779.

4) R. Sautebin and W. Raller: The Met. Society, Light Metals, (1985), 1301.

5) C. Vives and R. Ricou: Metall. Trans. B, 16B (1985), 377.

6) C. Vives and F. Adam: Proc. of EPM 1997, Vol. 2, M. Garnier, Paris, France, (1997), 205.

7) S. Asai: 129-130th Nishiyama Memorial Seminar, ISIJ, Tokyo, (1988).

8) M. Morishita, H. Tanaka and K. Ayata: Advances of MHD Application in Materials Processing, ISIJ, Tokyo, (1993), 69.

9) I. Sumi, K. Sassa and S. Asai: Tetsu-to-Hagané, 78 (1992), 447.

10) H. Nakata, M. Kokita and K. Ebina: Tetsu-to-Hagané, 80 (1994) 711.

11) T. Toh, E. Takeuchi, M. Hojo, H. Kawai and S. Matsumura: ISIJ Int., 37 (1997), 1112.

12) H. Kim, J. Park, D. Shim, H. Jeong and J. Kim: The 3rd Int. Symp. on Electromagnetic Processing of Materials, ISIJ, Tokyo, (2000), 236.

13) M. Tani, K. Shio, K. Wajima, E. Takeuchi, J. Tanaka and K. Miyazawa: The 3rd Int. Symp. on Electromagnetic Processing of Materials, ISIJ, Tokyo, (2000), 381.

14) T. Inoue, H. Nakata, K. Ayata and S. Ishiguro: The 3rd Int. Symp. on Electromagnetic Processing of Materials, ISIJ, Tokyo, (2000), 392.

15) H. Kim, J. Park, H. Jeong and J. Kim: ISIJ Int., 42 (2002), No. 2, 171.

16) J. Park, H. Jeong, H. Kim and J. Kim: ISIJ Int., 42 (2002), No. 4, 385.

17) G. Kim, H. Kim, K. Oh, J. Park, H. Jeong and E. Lee: ISIJ Int., 43 (2003), No. 2, 224 